\title{
Sentidos e Práticas em Saúde Mental em Comunidades Quilombolas no Estado de Rondônia
}

\author{
Eraldo Carlos Batista ${ }^{1}$ \\ ${ }^{1}$ Pontifícia Universidade Católica, RS, Brasil.
}

\author{
Katia Bones Rocha ${ }^{1}$ \\ ${ }^{1}$ Pontifícia Universidade Católica, RS, Brasil.
}

Resumo: O objetivo deste estudo foi compreender como os remanescentes quilombolas de duas comunidades do Vale do Guaporé no estado de Rondônia produzem sentidos sobre saúde mental. A partir de uma abordagem qualitativa foram realizadas entrevistas abertas e rodas de conversas com 18 participantes de ambos os sexos. A análise do material empírico foi realizada de acordo com as propostas de análise do discurso, sob a perspectiva da Psicologia Discursiva. Por meio do recurso teórico-analítico foram identificados três repertórios interpretativos sobre saúde mental: construção do sofrimento mental: reconhecimento e formas de lidar com os sintomas psiquiátricos; recursos utilizados pelos moradores da comunidade no cuidado em saúde mental; e consumo excessivo de bebidas alcoólicas como problema de saúde mental. Esses sentidos apontam para a necessidade de construção e implementação de intervenções e políticas públicas de saúde direcionadas a essa população que levem em consideração seus aspectos sócio-históricos e culturais.

Palavras-chave: Saúde Mental, Comunidade Quilombola, Produção de Sentidos.

\section{Senses and Practices in Mental Health in Quilombola Communities in the State of Rondônia}

\begin{abstract}
The objective of this study was to understand the meanings related to mental health by remnants of two communities in the Guaporé Valley in the State of Rondônia. This is a qualitative study using interviews and conversation groups with 18 participants of both sexes. The analysis of empirical material was carried out according to the discourse analysis proposals, from the perspective of the Discursive Psychology. Through the theoretical-analytical resource three interpretive repertoires on mental health were identified: 1) Construction of mental suffering: recognition and ways of dealing with psychiatric symptoms; 2) Resources used by community residents in mental health care; and 3) Excessive consumption of alcoholic beverages as a mental health problem. These meanings point to the need for the construction and implementation of interventions and public health policies directed to this population that take into account their socio-historical and cultural aspects.
\end{abstract}

Keywords: Mental Health, Quilombola Community, Production of Meanings. 


\title{
Sentidos y Prácticas en Salud Mental en Comunidades Quilombolas en el Estado de Rondônia
}

\begin{abstract}
Resumen: El objetivo del estudio fue comprender como los remanentes quilombolas de dos comunidades del Valle del Guaporé en el Estado de Rondônia producen sentidos sobre salud mental. A partir de un abordaje cualitativo se realizaron entrevistas abiertas y ruedas de conversación con 18 participantes de ambos sexos. El análisis del material empírico fue realizado de acuerdo con las propuestas de análisis del discurso ,bajo la perspectiva de la Psicología Discursiva. Por medio del recurso teórico-analítico se identificaron tres repertorios interpretativos sobre salud mental: construcción del sufrimiento mental: reconocimiento y formas de lidiar con los síntomas psiquiátricos; estrategias utilizadas por los habitantes de la comunidad en el cuidado de la salud mental; y el consumo excesivo de bebidas alcohólicas como problema de salud mental. Estos sentidos apuntan a la necesidad de construcción e implementación de intervenciones y políticas públicas de salud dirigidas a esa población que tenga en cuenta sus aspectos socio-históricos y culturales.
\end{abstract}

Palabras clave: Salud Mental, Comunidad Quilombola, Producción de Sentidos.

\section{Introdução}

Definidas como grupos populacionais remanescentes de antigos quilombos, segundo a metodologia utilizada pelo Ministério da Saúde, as comunidades quilombolas enquadram-se como um grupo minoritário dentro da população negra, constituindo uma representação da resistência dos negros brasileiros (Freitas, Caballero, Marques, Hernández, \& Antunes 2011). Seus costumes, tradições, condição social, cultural e econômica peculiares mantêm as semelhanças entre seus membros, distinguindo-os de outros setores da coletividade nacional, formando, assim, sua “identidade social” (Deschamps, \& Moliner, 2013).

As comunidades quilombolas no Brasil são múltiplas e variadas e se encontram distribuídas em todo o território nacional. Há comunidades que se localizam no campo e outras na cidade, sendo estas também denominadas de quilombos urbanos. Por meio de fortes laços de parentesco e herança familiar, essas comunidades se constituem e se afirmam desde o passado na luta pela liberdade (Furtado, Pedroza, \& Alves, 2014). Já as comunidades que estão localizadas fisicamente nas áreas rurais, notadamente em todas as regiões do Brasil, vivem em um relativo grau de isolamento geográfico e social. Como forma de subsistência, as comunidades quilombolas rurais, ao longo do tempo, implementaram e desenvolveram atividades produtivas e extrativas, seguindo a trajetória das atividades econômicas de cada região; contudo, o distanciamento espacial entre essas comunidades e a sociedade urbana também implicou desigualdades sociais e de assistência à saúde (Silva Filho, 2012; Oliveira, Pereira, Guimarães, \& Caldeira, 2015). Esses condicionantes sociais afetam ainda mais as comunidades que se encontram em isolamentos extremos, como, por exemplo, aquelas que se fixaram na região Amazônica, em decorrência, principalmente, da escassa infraestrutura e dificuldade de acesso aos serviços de saúde (Melo \& Silva, 2015).

As comunidades remanescentes quilombolas que vivem no contexto amazônico, embora possuam algumas características semelhantes às comunidades quilombolas de outras regiões do País, possuem algumas características próprias. Com o fim do poder dos jesuítas sobre os índios, intensificou-se o tráfico de africanos para a região, e a partir de então muitos mocambos foram formados por índios e negros. A partir desse período as comunidades quilombolas da região Amazônica mantiveram forte relação como as populações indígenas (Marin, 2009). Com isso, muitas residências quilombolas se fixaram em áreas de floresta bastante preservada.

Para os agentes em pauta, a floresta consiste em uma das formas de refúgio, fornecendo alimentos, matérias-primas para a construção de moradias e de embarcações. Os rios transformam-se em caminhos e forneceram alimentos, como peixes e quelônios. Nesses espaços, os quilombolas cultivam e desenvolvem 
técnicas sustentáveis de extração, pesca e agricultura condizentes com as especificidades da Amazônia (Cruz, 2012; Marin, 2009).

No que se refere às comunidades localizadas no estado de Rondônia, a chegada foi via o Rio Guaporé, que percorre quase todo o estado na fronteira com a Bolívia, na região do Vale do Guaporé. Por meio desses processos de formação da povoação, iniciou-se a resistência da escravidão, uma vez que os escravizados entraram nas matas, subiram os afluentes do Rio Guaporé e formaram os quilombos em diversas localidades (Cruz, 2012). Assim como outras comunidades da região Norte, as comunidades quilombolas guaporeanas passam, então, a se relacionar com as comunidades indígenas, caboclas, ribeirinhas e bolivianas no processo de criação e reprodução do seu modo de vida. Nesse entrecruzamento humano as culturas são intercambiadas, mesclam-se, superpõem-se, renascem, revigoram-se e administram suas atividades econômicas, segundo um conjunto de conhecimentos transmitido de geração em geração. Assim, as comunidades do Vale do Guaporé apresentam características muito particulares em termos de localização das moradias e trabalho, hábitos e costumes, que, em geral, seguem uma tradição e refletem o cenário socioambiental e econômico onde vivem e trabalham.

Nesse contexto, os saberes tradicionais foram fundamentais para a sobrevivência dessas comunidades, contribuindo para o desenvolvimento de formas próprias de se relacionar com o ambiente. Dessa maneira os quilombolas guaporeanos mantêm viva sua cultura, sua forma de lidar com a vida e a morte, com a saúde e com a doença, demonstrando possuir um profundo conhecimento prático dos aspectos da natureza que se relacionam com o seu bem-estar (Geertz, 2013). Por outro lado, essas comunidades ainda padecem de problemas crônicos e elementares, como a falta de serviços básicos, moradia, educação e, sobretudo, de acesso à saúde (Teixeira, \& Xavier, 2018), conforme outras comunidades rurais do País. Além disso, a localização em espaços de difícil acesso e as péssimas condições de infraestrutura dessas comunidades reverberam como desafios para o sistema público de saúde, pois dificultam a efetivação das ações e, consequentemente, impedem uma oferta qualificada dos serviços, especialmente na atenção primária e saúde mental (Freitas et al., 2011; Kochergin, Proietti, \& César, 2014; Silva, Dimenstein, \& Leite, 2013).
Diante do que foi exposto e da escassez de publicações que apontem e tornem conhecidas as condições de saúde mental da população quilombola, sobretudo daquelas que estão inseridas na região Amazônica, este estudo teve por objetivo compreender os sentidos produzidos sobre saúde mental pelos remanescentes de quilombolas de duas comunidades do Vale do Guaporé no estado de Rondônia, considerando o contexto social, cultural e histórico.

\section{Método}

Como abordagem metodológica, este estudo utilizou a pesquisa qualitativa sob a perspectiva da Psicologia Discursiva (Potter, \& Wetherell, 1987). Constituída como uma forma de inteligibilidade em Psicologia Social e situada no campo epistemológico do construcionismo social (Gergen, 1997), a Psicologia Discursiva enfatiza a linguagem construída historicamente e como construtora de realidades. A partir da possibilidade humana de aquisição da linguagem, essa perspectiva elege como objeto de sua investigação as construções linguísticas e gramaticais, os discursos e as narrativas de vários tipos mediante os quais as pessoas constroem conjuntamente realidades pessoais e sociais (Gergen, 1997; Rasera, 2013).

Dessa maneira, a Psicologia Discursiva busca compreender como o discurso realiza práticas sociais, ou seja, como as conversas e os textos são entendidos como partes de práticas sociais (Rasera, 2013). Ela estuda como as pessoas constroem, montam, solapam etc., relatos e descrevem e invocam estados e características psicológicas por meio das ações que o discurso realiza (Edwards, 2004).

A pesquisa foi realizada entre junho e dezembro de 2017 na Comunidade Santo Antônio do Guaporé, no Município de São Francisco do Guaporé, e na Comunidade Jesus, localizada no Município de São Miguel do Guaporé. Santo Antônio do Guaporé é uma comunidade formada por pretos de origem quilombola situada na área de confluência dos Rios São Miguel e Guaporé, no Sudoeste de Rondônia, à margem direita do Rio Guaporé, porção Sudoeste do Município de São Francisco, na fronteira entre o Brasil e a Bolívia (Teixeira, \& Xavier, 2018). Vivem na comunidade dez famílias com pouco mais de 50 pessoas, em situação de isolamento, o que as colocam em situação de vulnerabilidade social.

A Comunidade de Remanescentes Quilombolas Jesus constitui-se na mais afastada comunidade de 
remanescentes quilombolas rondoniense em relação ao Vale do Guaporé. Localizada a 108 km do Município de São Miguel do Guaporé, no coração de Rondônia, suas origens remontam à década de 1940, e os antepassados da família têm suas origens ligadas aos negros de Vila Bela da Santíssima Trindade.

Participaram do estudo 18 remanescentes quilombolas, 12 do sexo masculino e seis do sexo feminino, com idades entre 19 e 61 anos. Quanto à comunidade vinculada, dez participantes eram membros da Comunidade Santo Antônio do Guaporé e oito da Comunidade Jesus. Destes, nove afirmaram ser casados, um afirmou ser separado e oito, solteiros. Quanto à escolaridade, cinco se declararam analfabetos, quatro concluíram apenas as séries iniciais do ensino fundamental, três possuíam o ensino fundamental incompleto, dois, o ensino médio incompleto, dois, o ensino médio completo, um, o ensino superior incompleto e um possuía curso de especialização em educação. A seleção dos participantes foi realizada de forma intencional. De acordo com Creswell (2010), na pesquisa qualitativa o pesquisador escolhe aqueles que melhor ajudarão a entender o problema e a questão da pesquisa.

Como critérios para inclusão no estudo foram observados os seguintes: 1) ser descendente de remanescentes quilombolas; 2) morar na comunidade; e 3) ter idade igual ou superior a 18 anos. Os entrevistados serão apresentados com E1, E2, respectivamente.

Para a realização da pesquisa foram realizados três encontros em cada comunidade. O primeiro encontro foi com o líder da comunidade para apresentar o projeto e solicitar a autorização para a realização da pesquisa. O segundo foi realizado com os membros das comunidades convocados pelas lideranças para apresentação e explicação dos objetivos da pesquisa, seguidas de uma roda de conversa sobre a comunidade e sua relação com a saúde/saúde mental. Foram realizadas duas rodas de conversas em cada comunidade, sendo uma privilegiando os participantes mais jovens e outra com os demais participantes. De acordo com Edwards (2004), na Psicologia Discursiva a coleta de dados começa com um conjunto de materiais conversacionais que ocorrem naturalmente. $\mathrm{O}$ terceiro encontro teve como finalidade a realização das entrevistas individuais com aqueles que concordaram em colaborar com informações mais específicas sobre a temática proposta. Foram utilizados, ainda, a observação sistemática e o diário de campo como instrumentos de coleta de informações.
A análise das informações neste estudo teve como orientação a proposta de Análise do Discurso influenciada pela perspectiva da Psicologia Discursiva, privilegiando o conceito de repertório interpretativo, compreendido como "o conjunto de elementos que os falantes utilizam para construir versões das ações, processos cognitivos e outros fenômenos" (Potter, \& Wheterell, 1987, p. 149). O uso do conceito de repertórios interpretativos neste estudo apoia-se nas referências da Psicologia Discursiva, que enfatiza o aspecto do conteúdo no processo de produção de sentido (Rasera, 2013). Sob esse enfoque, o sentido é compreendido como uma construção social, um empreendimento coletivo, mais precisamente interativo, por meio do qual as pessoas, na dinâmica das relações sociais historicamente datadas e culturalmente localizadas, constroem os termos a partir dos quais compreendem e lidam com as situações e fenômenos a sua volta (Spink, \& Medrado, 2013). A partir dessa proposta, a análise das informações coletadas seguiu as seguintes etapas: a) leitura flutuante; b) transcrição na íntegra das entrevistas; c) leitura atenta do material construído e do caderno de campo; e d) análise dos repertórios interpretativos identificados nas informações colhidas (Potter \& Wheterell, 1987).

O projeto foi submetido à avaliação e aprovado pelo Comitê de Ética em Pesquisa da Pontifícia Universidade Católica do Rio Grande do Sul (PUCRS), sob o Parecer $n^{\circ}$ 2.410.908 e CAAE ${ }^{\circ}$ 79939417.7.0000.5336. Ressalta-se que para preservar o sigilo dos participantes os nomes foram substituídos pela palavra Entrevistado seguida do número referente à ordem em que foi realizada a entrevista.

\section{Resultados e discussão}

A análise do material coletado possibilitou a compreensão de que os sentidos produzidos por eles sobre doença mental são plurais e são construídos a partir das experiências e vivências cotidianas e da sua relação com a natureza e a cultura. Desse modo, a leitura e a interpretação das entrevistas possibilitaram a organização de três repertórios interpretativos:1)A construção do sofrimento mental: reconhecimento e formas de lidar com os sintomas psiquiátricos; 2) Recursos utilizados pelos moradores da comunidade no cuidado em saúde mental: ervas e plantas medicinais e práticas religiosas; e 3) O consumo excessivo de bebidas alcoólicas como problema de saúde mental. 


\section{A construção social do sofrimento mental: reconhecimento e formas de lidar com os sintomas psiquiátricos}

Neste eixo foi analisado o processo de construção de uma categoria discursiva que revela os sentidos produzidos acerca do conhecimento sobre a doença mental pelos remanescentes de quilombolas do Vale do Guaporé. Ainda, analisa como os membros das comunidades lidam com as pessoas que apresentam algum tipo de problema de saúde mental. A partir da pergunta: o que você entende por doença mental? Obtiveram-se respostas variadas, desde as de conteúdos técnicos e/ou com explicação clara dos sintomas até aquelas de conhecimento do senso comum como "problemas da cabeça", "uma pessoa doidona”, "perturbada da cabeça", "zonzeira", entre outras.

Durante os encontros foi possível identificar o uso de repertórios presente nos discursos da área da saúde. A análise das conversas a seguir revelou um conhecimento cotidiano permeado por saberes médicos, no qual a doença mental é percebida, entre outras coisas, como uma desordem emocional.

Eu acho que doença mental é quando a pessoa se encontra em desequilíbrio emocional, com ansiedade ou com algum tipo de transtorno, estresse, pânico, fobias. Acho que é isso (E 6).

Pessoa com um desequilíbrio emocional, fora da realidade. Na verdade, acho que problema mental é tudo que atrapalha a gente pensar racionalmente (E 12).

Acho que é a pessoa depressiva, que fica triste, mais no canto dela, que não fala com ninguém. Também pessoas mais estressadas, mais agitadas, mais agoniadas (E 5).

Essas falas mostram que as elaborações sobre doença mental constituídas por esses informantes parecem ser apropriações do conhecimento adquirido na sociedade e pelo contato com os serviços médicos.

No entanto, a maioria dos informantes deram respostas relacionadas às concepções do senso comum, oriundas das vivências e experiências cotidianas com a doença mental. Para essas pessoas o transtorno mental é compreendido como qualquer transtorno da cabeça associado a múltiplas variantes, como "pessoa desequilibrada", "meio atordoada", "perturbada da cabeça", "pessoa maluca", "meio doidona", conforme as falas a seguir:

A pessoa que tem algum problema na cabeça, essas coisas assim (E 12).

Penso que doença mental é uma doença que deixa a pessoa desequilibrada, meio atordoada, assim perturbada da cabeça, não fala coisa com coisa. Como as pessoas dizem, uma pessoa maluca, meio doidona [risos] (E 7).

Ah, estresse, com perturbação na cabeça, que não tem sossego, com zonzeira, acho que é isso (E 18).

Ah, sei lá. Uma pessoa com problema de cabeça? Assim perturbada da cabeça? Acho que é isso (E 13).

Esses depoimentos sugerem que os sintomas de transtornos mentais reconhecidos pelos entrevistados representam os modelos culturais de doença da comunidade, mas que também convergem com a forma com que pessoas de outros grupos percebem a doença mental. Um estudo realizado por Clemente, Loyola Filho e Firmo (2011) com idosos, em Minas Gerais, observou que a maioria dos entrevistados compreendia o transtorno mental como um problema de origem na cabeça, mente, cérebro ou ainda, como debilidade ou lesão.

No entanto, a análise das conversas, associada ao que se preconiza na literatura da área da saúde mental, possibilitou a compreensão de que os sentidos produzidos pelos informantes caracterizam uma pessoa fora da realidade, evidenciando a descrição de sintomas de transtorno psicótico.

Sei lá, uma pessoa maluca das ideias? Assim meio perturbado? (E 10).

Pessoa, assim, louca. Que fala sozinha, meio doida [risos] (E 9).

Coisa que não é verdadeiro, medo, tristeza. Fica com a cabeça perturbada não consegue pensar em nada direito. Também acho que é pessoa que fica falando sozinha por aí. Sei lá, acho que é isso [risos] (E 15). 
Pra mim é pessoa que perde o sentido (silêncio), assim, não tudo, mas um pouco do sentido. Pessoa que tem problema de cabeça, sabe, assim, meio perturbada. Pra mim é isso; é isso mesmo? (E 17).

A percepção do próprio adoecimento também aparece nas narrativas em termos de sensações vividas na dimensão corporal ou mental, como aquelas referidas na região da cabeça, como manifestação de um quadro patológico. "Eu... Pensei, né, mim mesma [risos]. Assim, eu fico ruim da cabeça, né, me dá aquela zonzeira, fico meio perdida no tempo. Então eu acho que eu tenho esse problema da mente. Fico agitada também" (E 16).

Em outro momento procurou-se averiguar sobre o quanto os informantes seriam capazes de reconhecer e descrever uma pessoa que apresentasse algum tipo de problema mental.

Então, eu nunca tinha parado pra pensar nisso [risos], mas agora o senhor falando... Aqui já teve um caso em que um rapaz, tinha vez que ficava muito agitado, agressivo, saía gritando (E 1).

Às vezes alguns aqui já ficaram, assim, um pouco perturbado [risos], mas não era doido não. Ficava assim meio que sem saber o que fazer, meio andando de um lado para o outro, mas depois passava [risos]. Mais que eu lembro foi só um rapaz aqui da comunidade uma vez, já faz tempo (E 11).

Ela (sobrinha) não podia ver sangue que saía gritando o que tivesse na frente ela chutava, podia machucar ela que ela não ligava, ela subia em cima das casas de assoalho e pulava lá de cima. Ela corria e vinha se pegava com a gente, aí falava que só ficava bem perto de mim [...] (E 17).

Rapaz, a gente tinha uma prima que ela não ficava sozinha. Acho que é síndrome do pânico, né, tinha perturbações (E 15).

[...] ficar muito tempo dentro de casa, não sai. Senti medo, fica com a cabeça perturbada... É isso (E 18).

Por meio dos discursos apresentados é possível observar que os sistemas explicativos do quadro pato- lógico pelos informantes não são homogêneos. O uso da combinação de vários elementos, como "agitação", "agressividade", "desorientação", "fobia”, entre outros, foi verificado na descrição e na caracterização de um quadro de transtorno mental.

As conversas cotidianas também evidenciaram a variabilidade de sentidos que os informantes produzem sobre a sintomatologia de um quadro depressivo. Para alguns, a pessoa com depressão é vista como incapaz, enfraquecida, sem forças, lenta, cansada, com as suas capacidades de raciocínio e decisão diminuídas, com as suas possibilidades de vida comprometidas: "[...] a pessoa ficar sem querer fazer nada, ficar pelo canto e tal” (E 12) ou “[...] (ela) ficava agoniada, chorava, ficava muito triste. Num comia, num queria ver e nem conversar com ninguém e só ficava dentro do quarto" (E 13).

Algo bastante interessante foi a utilização dos termos "banzú" ou "landú" para descrever as pessoas com sintomas depressivos. A utilização dessas palavras parece ser uma variação do termo "banzo" utilizado para definir uma enfermidade mental, uma variante do estado de tristeza e de depressão psicológica causado pela desculturação, nostalgia e saudade da África relatados pelos escravos após o desembarque no Brasil (Oda, 2013). Algumas falas ilustram essa concepção:

Tem umas pessoas que você percebe que elas estão quase querendo se isolar, né. Tem uma senhora mesmo que eu já percebi ela bem abatida mesmo. O outro é um tio nosso que tem aqui. Ele de uns tempos pra cá tem ficado bem isolado, e pra começar ele já mora só, a convivência dele é ele e a filha dele, e ele tem se isolado. [...] a gente percebe que ele fica meio desorientado. Aí você percebe que ele tá entrando em depressão. Aqui na comunidade a gente chama isso de "landú" (E 7).

[...] de vez em quando uns fica assim, não querendo falar nada com ninguém, meio triste, num canto meio "banzú", mas depois passa e volta a ficar normal (E 11).

[...] inclusive eu sou assim, eu não ando muito, muito bem. Ultimamente só quero ficar dentro de casa, não quero ver ninguém. Se pudesse eu ficava isolado de todo mundo, meio "banzú" (E 4). 
Diante das conversas que descrevem os sintomas da enfermidade, pode-se notar como essa ressignificação do Banzo está inserida no contexto atual dessa população. Como afirma Oda (2013, p. 108), "atualmente o Banzo continua sendo uma entidade presente no imaginário brasileiro sobre os sofrimentos dos escravos". Tal explicação pode ser compreendida por meio da forte manutenção dos valores simbólicos e afetivos presentes nas comunidades. De acordo com Furtado et al. (2014), a cultura quilombola, enquanto esfera social, permite aos indivíduos expressarem seus valores e princípios e vincularem-se de forma simbólica e afetiva ao grupo.

A patologia também foi interpretada como sintomas passageiros que oscilam alternando o estado de humor da pessoa: "É assim, hoje o cara tá bom, aí quando é amanhã, fica uns dois, três dias assim, banzú, sem motivo. Se isola não quer conversar com ninguém, muda da água pro vinho. [...] tipo, hoje ele conversa com o senhor, aí no outro dia já tá de cara fechada." (E 7) ou como algo normal: "Olha, às vezes uns fica meio triste, mas acho que é normal, né? Toda pessoa fica triste de vez em quando" (E 2).

Para alguns informantes o isolamento social e a tristeza estão associados à perda de familiares e amigos. Por viverem por muito tempo em meio à floresta, com pouco contato social, os quilombolas do Vale do Guaporé construíram fortes laços afetivos entre os familiares. Portanto, a perda de um ente parece causar forte impacto emocional em alguns moradores das comunidades, como mostram os trechos a seguir:

Assim, tem algumas pessoas que são sem motivo, outras quando acontece alguma coisa, como, por exemplo, a morte de um parente, geralmente as pessoas fica de "banzú" (E 6).

Olha, isso acontece muito quando a gente perde um parente, né. Aqui sempre que morre um parente, tem gente que fica assim por muito tempo. [...] já teve caso da pessoa ficar foi um ano $\operatorname{assim}($ E 3).

Nesse caso, o Banzo, apresentado como enfermidade causada pela exacerbação do sentimento de saudades ou outra paixão triste (Oda, 2013), parece explicar o sofrimento e o comportamento dessas pessoas diante da perda. Para Furtado et al. (2014), a comunidade quilombola, por ser um espaço de trocas e compartilhamento de conteúdo simbólico-afetivo, permite aos sujeitos se sentirem pertencentes a esse universo particular e se apropriarem de valores e conteúdos inerentes à realidade em questão.

Outros sintomas de doença mental reconhecidos pelos informantes foram os relacionados ao estresse e ao transtorno do humor. A descrição das pessoas que apresentam esses sintomas ganhava adjetivos como "nervosinhos" e "estressadinhos" dos informantes: "Olha, rapaz, tem... Às vezes tem uns meio nervosinhos [risos]" (E 2). Alguns até apresentavam as características da pessoa:

Ah, fica enjoado, né. A gente fala uma coisa com ele e responde mal, e daí em diante já fica estressadinho [risos] (E 2).

[...] que ficam muito estressado, não pensa pra falar. Fala bobagem. Pessoa que não tem sossego (E 18).

Tenho percebido também umas pessoas um pouco estressadas, não são muitas, mas tem. [...] E não era assim, como o senhô viu aqui as pessoas são assim, mais tranquilas, falam pouco, mas ultimamente tem uns ficando um pouco estressadinhos [risos] (E 12).

Outro fato interessante refere-se à forma de a comunidade lidar com as pessoas em momentos de crises. Sobre quais procedimentos eram tomados em relação às pessoas que apresentassem algum tipo de "perturbação na cabeça", muitos consideravam esses quadros como temporários e transitórios, não havendo a necessidade de nenhum tipo de intervenção: "Nada [risos]" (E 1) ou “[...] não tem muito que fazer. É deixar a pessoa quieta até melhorar" (E 3) ou, ainda, que os sintomas são passageiros: "Ah, é só deixar eles pra lá que passa [risos]" (E 2); "Rapaz, nesse caso a gente não faz nada não, porque isso é só uns dias depois passa" (E 11). Este último até exemplifica: “[...] já vi outros aqui que estava assim e passou. Daqui um pouco tá bom também [risos]". Embora essas conversas possam produzir sentidos de descaso, abandono ou negligência por parte da comunidade com os que se encontram em sofrimento mental, vale lembrar que a população negra tem seu próprio conceito de cuidado em saúde mental (Santos, 2017). Tal compreensão pode ser identificada nos relatos que 
descrevem o costume de algumas pessoas das comunidades, durante as crises de um transtorno mental, de se refugiarem em meio à floresta. Nas falas a seguir fica evidente que, independente da patologia, o isolamento no meio da mata parece ser uma forma encontrada de aliviar o sofrimento.

Tem uma sobrinha minha aí que corria [...] pegava essa estrada aí e se mandava correndo. Às vezes, pra dentro do mato e demorava voltar (E 17).

[...] uma tia minha, acho que depois que meu avô morreu, ela ficou com depressão. Ela ficava assim nos cantos, não falava nada. Muito quieta, ficava sentada na beira da mata (E 12).

[...] ela [prima] não tinha vontade de sair, não tinha alegria, às vezes ficava quieta lá na beira do mato sentada em um tronco de árvore por muito tempo de cabeça baixa. Acho que foi depois que meu vô morreu... Ela ficou muito tempo assim. Até hoje ela ainda é um pouco assim (E 18).

Eu lembro de um rapaz, sobrinho nosso, que ficou perturbado da cabeça. Ficava andando de um lado para o outro assim meio tonto, né [risos], meio sem rumo [risos]. Às vezes, ele ia pras bera do mato, ficava mais calmo e depois voltava [risos] (E 3).

Essas falas revelam que esse momento de retirada é um tempo necessário que essas pessoas permitem para sua recuperação, que o indivíduo em sofrimento mental que vive na sociedade produzida pela lógica capitalista não consegue ter. Por outro lado, esse comportamento também pode ser explicado pela relação estabelecida entre as comunidades guaporeanas e a natureza. Como afirmam Teixeira e Xavier (2018), as matas foram o elemento principal de continuidade da vida após a escravidão, percebidas pelas comunidades negras como uma extensão da própria casa, e os vínculos existentes entre os membros das comunidades guaporeanas com o espaço natural florestal e fluvial são profundos.

\section{Recursos utilizados pelos moradores da comunidade no cuidado em saúde mental}

Os remanescentes de quilombolas do Vale do Guaporé integram o complexo sociocultural da Ama- zônia brasileira, representado também por indígenas, ribeirinhos e caboclos, os quais tiveram uma forte influência sobre os saberes e fazeres desses grupos (Pereira, \& Coelho-Ferreira, 2017), sobretudo no tratamento de doenças diante das dificuldades de acesso à saúde. Sob esse prisma, esse repertório procurou analisar o discurso produzido em relação ao uso de ervas e plantas medicinais como recurso de tratamento das doenças enfrentadas pelos remanescentes quilombolas do Vale do Guaporé.

Durante as entrevistas e rodas de conversas observou-se que o uso de chás de ervas e plantas medicinais ainda é muito comum nas comunidades em questão. Essa prática foi justificada pelos informantes pela tradição e aspectos culturais passados de geração em geração, mas também para suprir a falta de assistência à saúde pelo poder público. Ao ser interrogados se ainda existe o costume do uso de chás para o cuidado em saúde, referiram:

Sim. Até mesmo porque, como o senhor viu, aqui é muito longe da cidade, então nem sempre tem remédio pra tudo. Agora o senhor imagina como era antigamente. Então, as mulheres aprendem desde de pequeninhas a fazer chás. Os chás é muito importante pra comunidade. Aqui as pessoas usam chá pra tudo [risos] (E 1).

[...] de primeiro usava bastante por causa do conhecimento que tinha sobre as plantas e também porque a embarcação que tinha aqui não facilitava muito, aí era mais viável você fazer um chá (E 7).

De acordo com Amorim, Tomazi, Silva, Souza Gestinari e Figueiredo (2013), as práticas relacionadas ao uso popular de plantas medicinais são alternativas que muitas comunidades têm como viável para o tratamento de doenças ou manutenção da saúde. Nas comunidades do Vale do Guaporé essas práticas de cuidado fazem parte da tradição das comunidades e são repassadas para as gerações mais novas.

O tratamento com chás nas comunidades quilombolas faz parte da nossa cultura. Isso se deve ao fato de que quando os mais antigos chegaram aqui nessa região não havia outras formas de tratamento, era só através de chás ou por meio de rezas, simpatias, benzição. E essa prática foi 
passando de geração em geração. Então, sempre que alguém tem algum tipo de doenças menos graves ainda se trata com chás, mesmo nos dias de hoje (E 6).

A reprodução dessas práticas de cuidado deixadas pelos antepassados dos remanescentes revela-se como um saber local que está sendo repassado para as novas gerações (Geertz, 2013). Dessa forma, a cultura mantida nessas comunidades deve ser compreendida a partir de uma teia de significados criados pelo próprio homem em um contexto de particularidades histórico-culturais permeado por um imaginário social que remete aos tempos de escravidão, com histórias de resistência e luta (Furtado et al., 2014).

As análises das conversas cotidianas na comunidade também revelaram o quanto a continuidade dessa tradição parece estar comprometida, como afirmam os participantes: "Antigamente fazia mais, mas ainda tem gente que faz" (E 2) e que agora vem diminuindo, embora ainda esteja presente na cultura quilombola: "[...] quem sabe mais é os de antigamente, né, mas ainda tem" (E 10). "Rapaz, ainda faz, mas também não é mais como era antes. Hoje é poucos que tratam com ervas" (E 11). Em outro momento o entrevistado refere-se às pessoas mais idosas e às mulheres, principalmente as mães, como agentes principais na realização dos chás: "As pessoas mais velhas, principalmente as mulheres, as mães faz chá para curar algum tipo de doença, tipo gripe, essas coisas. Acho que todos nós já tomamos algum tipo de chá" (E 8). Tal constatação pode ser compreendida pelo fato de que as pessoas mais velhas, sobretudo as mulheres da comunidade, possuem reconhecidos saberes acumulados representados por um conhecimento amplo e diversificado sobre plantas medicinais das florestas guaporeanas. Estudo realizado por Pereira e Coelho-Ferreira (2017) na comunidade Tauerá-Açú, inserida no Território Quilombola Ilhas de Abaetetuba, no estado do Pará, concluiu que as plantas medicinais foram indicadas para 57 problemas de saúde.

Com o atendimento em saúde oferecido pelo poder público (mesmo que escasso), o uso de chás para o tratamento de várias doenças foi substituído por terapias medicamentosas. No entanto, o tratamento com plantas e ervas medicinais é visto de forma muito positiva pelos moradores das comunidades, como mostram as falas a seguir:
[...] isso aí ninguém não deixa, né. Todo lugar tem. Eu, vichi maria, eu tive que ir no hospital uma vez nessa idade que eu tenho, só uma vez. Sempre era tratado com ervas (E 4).

Pra mim ajudou, né, porque se eu ficasse em pé parecia que eu ia cair. Depois que tomei os chás melhorei muito (E 16).

Quando meu irmão não tava bom do fígado o que curou ele foi os setes pedaços de raiz de lima com raiz de picão. Os chás sou sempre eu que faço, né (E 17).

É interessante lembrar que a Política Nacional de Saúde Integral da População Negra (PNSIPN) dialoga com a Política Nacional de Desenvolvimento Sustentável dos Povos e Comunidades Tradicionais (PNPCT), instituída em 2007. Essa última tem como objetivo a promoção da saúde por meio de prestação de um cuidado culturalmente seguro e eficaz. Nesse sentido, o reconhecimento de que esses saberes são constituídos e constituintes nas e pelas relações culturais e sociais dessas comunidades é fundamental para a produção de conhecimento que viabilize as estratégias de atendimento à saúde dessa população.

Outro aspecto bastante interessante é a força exercida pelas práticas religiosas como recurso de cuidado em saúde, especialmente em saúde mental, na concepção dos moradores das duas comunidades investigadas. A partir dos discursos dos informantes pode-se perceber o quanto a religiosidade nas comunidades impera uma cultura de saber e poder entre os remanescentes de modos diferenciados, reproduzindo costumes e crenças que se fazem presentes há anos na população negra. Nas comunidades guaporeanas a religiosidade popular responde pelas tradições culturais locais (Teixeira, \& Pinto, 2013).

A cura de doenças por meio das práticas religiosas revela a importância da presença do benzedor, o qual é figura marcante nesse grupo. Em toda família já teve algum membro que foi ao benzedor. "Ah, às vezes a gente vai num rezador" (E 15). "Já fui, porque quando está assim com problema sai atrás de onde tem ajuda, né?" (E 14). “[...] já levei ela (filha) e minha irmã lá embaixo também sempre vai” (E 13).

A religião liga as pessoas ao plano do sagrado e a uma divindade que opera cuidados e cura (Silva et al., 
2013). Os relatos revelaram o quanto a religiosidade é uma força usada nas comunidades na resolução de problemas relacionados à saúde de seus membros e como estes acreditam na eficácia do cuidado à luz de suas tradições religiosas.

Ir no benzedor e rezar é bom. Dessa vez eu fui, e ele me falou que eu tava com a espinhela caída; aí ele rezou, e foi bom, sarou. Mês passado mesmo, eu estava aperreada e fui no rezadô e melhorei (E 13).

[...] acho que benzer ajuda muito. Acho que é importante o rezador na comunidade, ajuda muito, né, tratar das pessoas. Acho que tem que ter. Tem hora que não tem como ir no médico, no hospital, né. Também acho que tem coisa que é só benzer mesmo, não precisa ir no médico (E 14).

Compreender a força expressiva da religiosidade presente no cotidiano dessas pessoas é considerar suas expressões por meio de seus elementos sócio-históricos e culturais devidamente contextualizados onde essas comunidades se inserem. Nas palavras de Bourdieu (2015), a religiosidade é apresentada com papel preponderante, pois as relações simbólicas manifestadas e desenvolvidas pelas comunidades constituem um sistema estruturado de percepções e conceitos sobre o mundo, fazendo, assim, um sistema de "estrutura estruturante", sendo objeto de conhecimento e construção do mundo dos objetos, como formas simbólicas.

Outro fato relevante é a constatação de uma reverência aos benzedores antigos da comunidade pelos informantes do estudo. Nos trechos a seguir os entrevistados utilizam da memória para construir seus discursos sobre as práticas religiosas utilizadas como recurso de cuidado em saúde na comunidade. De acordo com Meneghel e Iñiguez Rueda (2007), a memória ajuda a compor uma narração, estabelece uma conversação com o passado, mostra qual a chave para interpretá-lo e quais as credenciais que avaliam sua verossimilhança.

Já teve mais; meus pais era tudo rezadô, salvaram várias vidas, meu pai e a minha mãe, mas depois que eles morreram os rezadores foram diminuindo, uns foram embora (E 4).
Antigamente tinha mais, mas agora quase não tem rezador aqui. A minha vó era rezadora, ela rezava, e as pessoas melhoravam (E 15).

Os mais velhos já falavam que bem antigamente tinha, mas eu não sei muito sobre isso, não senhor (E 4).

[...] quando meu pai era vivo rezava mais, depois que ele faleceu ninguém reza quase (E 16).

Se não fosse os rezadores de antigamente muitas pessoas tinham morrido aqui. Rezadores e os chás, né? Porque não tinha atendimento de saúde, então, né, todo mundo se tratava ou era com chá ou com reza. Por isso tinha os benzedores, e tratavam, sim. Muitas pessoas foram curadas (E 8).

Esses discursos reafirmam as práticas religiosas por meio das rezas e os chás como as únicas possibilidades de tratamento nas comunidades ao longo do tempo. A pouca assistência em saúde continua sendo um problema que afeta a vida dessa população. A falta de atendimento médico exige constantes deslocamentos dos que permanecem na comunidade. As doenças mais graves exigem que o paciente e, não raro, seus familiares se mudem da comunidade para assegurar algum tipo de tratamento prolongado em áreas urbanas (Teixeira, \& Xavier, 2018).

Rezadô é mais difícil ainda, mas tem. Inclusive eu tenho um primo que é bom rezador, ele mora em Costa Marques em outra comunidade (E 11).

Já teve mais, mas hoje, assim, tem aqueles que benzem, mas não assim como aqueles rezador típico, acredito que não tem mais. Mas já teve, $\operatorname{sim}($ E 5).

[...] sempre tem. Ultimamente a minha tia é que é a rezadora. Antigamente era meu avô (E 12).

Nessas falas, as práticas religiosas são percebidas como costume passado pelas gerações mais velhas. Para Santos (2017), a oralidade como pedagogia que privilegia o encontro entre o mais velho e o mais novo é um modo de transmissão do saber não mediado nem conduzido pelo livro, mas pela aproximação 
entre experiências de gerações distintas. O depoimento a seguir corrobora tal afirmativa: "Os costumes que nós temos aqui é desde o meu avô que deixou pra nós, mais de origem africana. Eles aprenderam com os pais ou avós deles e foram passando para as gerações mais novas" (E 12).

Ao comparar a eficácia do cuidado em saúde mental realizado por um profissional de saúde especializado e um rezador, esta entrevistada foi enfática ao atribuir à reza a melhora do quadro clínico de um familiar.

Nós levamos ela na psicóloga, mas ela não falava nada. Aí a gente parou de levar. Aí levamos ela mais no rezador, e as simpatias que eu fiz também, creio que foi isso que melhorou ela, porque depois ela ficou boa. Então, eu penso que essas coisas resolvem melhor com rezador (E 17).

Nas análises feitas percebe-se o quanto a religiosidade no contexto discursivo deu sentido para as curas realizadas por meio de benzimentos. Também como essas práticas articulam com o cotidiano dessas pessoas, presentes nos mais diversos cenários da cultura das comunidades guaporeanas. Nos depoimentos a seguir a fé é materializada nas curas de diversas doenças, na concepção desses entrevistados:

Olha, eu acredito. Como the falei meus pais curaram muitas pessoas aqui, de todo tipo de doença (E 4).

[...] esse filho da minha tia, ele rezava também pra quebrante, dente caído, porque isso são doenças que só curam com reza. Tratava, vamos supor, se a pessoa levava um corte e dava uma doença chamada vermelha, ficava tudo vermelho ao redor ali, aí isso era curado com reza. (E 11).

Quebrante, espinhela caída. Meu pai benzia tudo, dor de dente, dor de ouvido, rezava e melhorava (E 16).

Ah, mais quando tinha perturbação, né. Rapaz, assim, pessoa perturbada da cabeça, né, aqui muitos acreditam que pode ser trabalho feito, né, pra essa pessoa. Daí só reza mesmo para curar ele (E 12).
As conversas revelaram que as práticas religiosas, sobretudo as de matrizes africanas, não são bem compreendidas pela comunidade não negra, gerando certo desconforto em alguns membros da comunidade, o que pode explicar a negação da prática entre alguns dos informantes: "Num sei falar, não, sinhô" (E 13) ou, ainda: "Aí nem sei. E essas coisas não pode contar, não, sinhô" (E 17). "Não, senhor, aqui não tenho conhecimento" (E 4) ou, ainda: “[...] Isso é comum nas comunidades, embora as pessoas não falam muito [risos]" (E 12). Esse informante justifica sua resposta:

Eu acho que é por causa que as pessoas de fora da comunidade não entendem direito sobre isso. [...] a maioria das pessoas não negro não compreende essas rezas ou benzimentos como prática de tratamento como outro qualquer. Sei lá eles acham que é trabalhos feitos, macumba, esses tipos de coisas, mas na verdade não é (E 12).

Essa fala parece evidenciar que a omissão ou o fato de esconder a prática religiosa de matriz africana ainda é muito comum nas comunidades negras. Por essas práticas serem encaradas de maneira negativa pela sociedade não negra, muitas vezes eles "precisam silenciar e omitir sua pertença religiosa para se protegerem das situações de preconceito, discriminação e intolerância religiosa" (Caputo, 2012, p. 20).

Essa interpretação pode explicar o fato de que apenas uma pessoa que exerce a função de rezador nas comunidades fale de suas práticas, mesmo demonstrando certa preocupação: “[...] não é que a gente gosta dessas coisas, mas a família, né, nós somos descendentes dessas "coisas" [religião africana], a família toda" (E 17). Para essa informante, ser rezador não é uma questão de escolha: "A gente quer escapar, mas não dá. Meu irmão fala que não gosta, mas daqui a pouco tá lá na benzedeira." Contudo, ela faz algumas ressalvas: “[...] mas agora tem que tomar mais cuidado [...], porque sempre tem um que apunhala pelas costas, né" (E 17). Ao ser questionada sobre "apunhalar pelas costas", a entrevistada deu a seguinte explicação: "Pessoas que falam que a gente só faz o mal, tipo trabalhos para os outros, essa coisa de macumba" (E 17). Essa fala revela que o preconceito com as práticas religiosas de matriz africana ainda está presente na sociedade. A Política Nacional de Saúde Integral da População Negra (PNSIPN) destaca em seu texto o reconhecimento dos saberes e práticas populares 
de saúde, sobretudo os saberes de matrizes africanas. Geertz (2008) concebe a cultura como um universo de símbolos e significados que permite a um grupo interpretar sua experiência e guiar suas ações. Para o referido autor, a cultura fornece o vínculo entre o que os homens são intrinsecamente capazes de se tornar e o que eles realmente se tornam.

\section{0 consumo excessivo de bebidas alcoólicas como problema de saúde mental}

Neste repertório o caráter dialógico e participativo de uma conversa com conteúdo sobre o consumo de álcool na comunidade permitiu que os discursos revelassem os marcadores sociais associados ao consumo de bebidas e a influência da tradição e da cultura na perpetuação do hábito. Em conversas com quatro jovens sobre consumo de bebidas alcoólicas, o assunto foi abordado com muito humor, evidenciado por meio de risadas, metáforas e ironia entre os entrevistados como estratégia na construção das respostas. Ao ser interrogados se na comunidade as pessoas tinham esse hábito, a primeira manifestação foi não verbal: "todos se olharam e deram muita risada" (Diário de Campo), em seguida respondem que sim, "Bebem, de vez em quando tomam [risos]" (E 4); "de vez em quando a gente bebe" (Entrevistado 3), outros utilizavam de figura de linguagem para relatar a quantidade do consumo: "Rapaz, a turma gosta um pouquinho [risos]" (E 2) ou, ainda: "Bebem, e não é pouco não [risos]" (E 11). A conversa ganha sustentação quando um jovem aponta para um lado e diz: "É só olhar ali [várias latinhas de cerveja vazias] [risos]" (E 14). De acordo com Meneghel e Iñiguez Rueda (2007), a ironia é uma ferramenta poderosa que se concretiza dando um significado oposto à literalidade das palavras. É um recurso que questiona e solapa os discursos dominantes.

O tipo de bebida consumida na comunidade parece ter sofrido mudanças ao longo do tempo, como mostram os seguintes depoimentos: "[...] de primeiro aqui não tinha cerveja, né, era só na cachaça, cachaça e álcool, que é álcool de farmácia e um que vinha da Bolívia" (E 6). Agora as bebidas comumente consumidas nas comunidades são a cerveja e a aguardente: "Cerveja e Velho Barreiro [aguardente], né” (E 9).

Quando questionados se na comunidade não havia restrições quanto à idade para consumir bebidas alcoólicas, um dos entrevistados responde nas entrelinhas: "Rapaz, aqui todo mundo gosta um pouquinho [risos]" (E 2). Ao dizer "todos", revelou que os mais jovens também consumiam. Quando a pergunta foi feita de forma direta: "Os adolescentes também bebem?", o mesmo participante dá uma resposta afirmativa, porém amenizada e de forma mais séria: "Não assim igual os mais velhos, mais bebe um pouco" (E 2). Outro confirma ressaltando que apenas os adolescentes do sexo masculino bebem: "Os homens sim, [...] até os mais novos" (E 15), ainda que independentemente da idade, o consumo associa-se ao costume da comunidade: "[...] tanto os mais velhos quanto os mais novos, acho que já é costume mesmo” (E 14). Ao ampliar a pergunta se crianças também bebiam, obteve-se uma resposta negativa: "Adolescentes bebem, crianças não" (E 6). Em nenhum momento as mulheres foram mencionadas sobre o uso de álcool nas comunidades. A faixa etária demarcada como iniciação ao consumo de bebidas alcoólicas foi a partir dos 14 anos: "Ah, dos 14 pra frente já começa. Aí começam na cerveja e depois o que tiver eles bebem" (E 7). Foi bem interessante esse discurso porque revela que nas comunidades quilombolas as pessoas que fazem uso de álcool passam por um processo de transição aprendido por meio das relações interpessoais construídas e estabelecidas socialmente entre os pares.

Quando interrogados sobre a frequência em que as pessoas bebem álcool na comunidade um participante respondeu: "Quando tem [risos]" (E 9), outro completou a frase: "[Risos] se tiver, [bebe] todo dia [risos], aqui é normal beber [...]" (E 14), e todos riram muito (Diário de Campo). Outro participante faz uma ironia à pergunta afirmando ser mais fácil dizer a não frequência do consumo: "Rapaz, a juventude hoje, se tiver eles bebem à vontade, e aqui a não frequência é a falta de álcool [risos]" (E 5).

Essas afirmativas foram reafirmadas em outros momentos e locais da pesquisa. "Rapaz, quando chega a bebida geralmente bebe o tempo todo, até acabar ou cair [risos]". (E 2). "Uma vez por semana ou quando tem vontade [risos]”. Quando acaba vão lá na rua e pegam cerveja e trazem pra beber [risos]" (E 4). "Se tem bebida, as pessoas se reúnem e vão beber e conversar até aguentar, né [risos]". (Entrevistado 8). "A gente bebe mais é quando tem algum tipo de festa, tipo de aniversário de alguém, daí vai na cidade e traz a bebida, e a gente bebe até acabar [risos]" (E 10).

Nessas falas o consumo de álcool tem forte conotação cultural e de sociabilidade nas comunidades. Ou 
seja, a presença da bebida alcoólica atua como mediadora dos encontros entre as pessoas. Para alguns dos entrevistados o consumo excessivo de bebida pode estar associado aos costumes das comunidades: "Olha, aqui bebe mais é nas festas, mas sempre que alguém vai na cidade traz bebidas, faz parte dos costumes da comunidade beber" (E 2). É visto como tradição: "É coisa, assim, que já faz parte da tradição. Se tem festa tem bebida, e aí todos bebem" (E 11). Visto que o hábito de consumir bebida alcoólica nas comunidades quilombolas se perpetua de geração em geração, acaba sendo culturalmente e socialmente aceito (Partelli, 2016).

Uma concepção bastante interessante sobre o consumo excessivo de bebidas alcoólicas na comunidade foi sua atribuição à falta de lazer e entretenimento na comunidade. Para alguns informantes, principalmente os mais jovens, beber é a única forma de diversão nesses espaços. "Sempre foi assim. Todo mundo bebe. Mas, também, não tem diversão aqui!" (E 14). "Rapaz, aqui é costume, acho que faz parte do povo daqui. Também penso que as pessoas bebem porque não tem outra coisa pra fazer aqui. Então, eu acho que beber é uma diversão" (E 8). "Aqui na comunidade bebe todo mundo [risos], mas também a única diversão aqui é as festas. Então, quando não tem festa não tem nada pra fazer, daí se tem bebida eles vão beber" (E 11).

Esses discursos mostram que a falta de investimento em esporte e lazer nas comunidades refletem negativamente na constituição desses jovens enquanto sujeitos sociais. Um estudo realizado por Silva e Menezes (2016) concluiu que as poucas atividades de lazer, somadas a outros marcadores sociais, como as relações de gênero, o preconceito sofrido por serem negros e/ou quilombolas, são situações que, de modo interseccionado, repercutem no uso de álcool entre os jovens investigados.

Outro aspecto importante que alguns participantes levantaram é a atribuição às mudanças ocorridas, como o acesso à cidade e as infraestruturas que têm chegado à comunidade, como facilitadoras do consumo de bebidas alcoólicas.

Esse eu vejo como um grande problema na nossa comunidade. Porque, assim, sempre as pessoas da comunidade gostaram de beber, acho que isso faz parte do nosso costume, da nossa cultura. Mas antigamente era assim, quando alguém ia na cidade trazia a bebida, geralmente era pinga ou vinho. Daí sempre, assim, nos finais de semana ou nos fins de tardes os homens reuniam e bebiam, mas mesmo era quando tinha festa na comunidade. Agora que a gente tem acesso com facilidade de ir na cidade, a bebida faz parte do dia a dia das pessoas aqui. Bebem todos os dias. Se vai na cidade e traz três caixas de cervejas, porque agora eles tomam mais é cerveja, né, daí vai bebendo até acabar, sem parar, não importa se é segunda ou terça, é qualquer dia [risos]. Além disso outra coisa que facilitou é agora termos energia; então, todos têm geladeira para gelar a cerveja [risos] (E 12).

Agora que temos energia as pessoas assistem televisão, mas é só isso. Então, se reúne para beber (E 14).

Essas conversas mostram que as interações entre o tradicional e o moderno, bem como o rural e o urbano como processo vivido pelos remanescentes do Vale do Guaporé podem ser compreendidas por meio do conceito antropológico de hibridação, o qual é utilizado para designar as misturas interculturais propriamente modernas, entre outras, aquelas geradas pelas integrações dos Estados nacionais, os populismos políticos e as indústrias culturais (Canclini, 2013). Nesse caso, as comunidades rurais quilombolas interagem com a cultura urbana por meio das novas tecnologias e hábitos até então desconhecidos por essa população. Ou seja, ao lado de todo procedimento de transformação dos espaços naturais produziu-se uma grande transformação dos padrões culturais das populações tradicionais guaporeanas (Teixeira, \& Xavier, 2018).

A preocupação com o consumo excessivo de bebidas alcoólicas foi mencionada por um informante ao defender a necessidade de tratamento de alguns membros da comunidade considerados por ele como alcoolistas: “[...] acredito que vários deveriam passar com um especialista, mas duvido muito que eles irão [risos]. Na verdade, ninguém aqui vê a bebida como um problema de saúde" (E 12). Essa fala reflete a realidade dessas e de outras comunidades quilombolas do País. Pesquisas realizadas no Brasil têm reforçado que o consumo excessivo de álcool em comunidades quilombolas é visto como problema e agravo de saúde (Cardoso, Melo, \& Cesar, 2015; Marques et al., 
2014; Melo, \& Silva, 2015). Esse cenário aponta para a necessidade de implementação e efetivação de políticas públicas que tenham como meta a orientação e a prevenção do alcoolismo nessas comunidades.

\section{Considerações finais}

Neste estudo buscou-se descrever os sentidos produzidos sobre a saúde mental por remanescentes de duas comunidades quilombolas. Além disso, esta pesquisa analisou as práticas de cuidado em saúde mental levando em consideração os aspectos culturais e religiosos dessas comunidades.

Os sentidos apresentados por meio das práticas discursivas dos moradores das duas comunidades quilombolas são produzidos no cotidiano das comunidades com base no senso comum. Os principais sintomas de doença mental reconhecidos foram os relativos ao transtorno psicótico, este descrito como agitação da pessoa e/ou comportamentos atípicos, como andar de um lado para o outro, correr, gritar, adentrar a floresta; sintomas depressivos, como tristeza, isolamento, apresentados como banzú; o estresse ganhou conotação de pessoa nervosa, além de quadros fóbicos.

O estudo mostrou, ainda, que a comunidade mantém viva sua cultura e tradição sendo estas passadas de geração em geração. As práticas religiosas e o tratamento com ervas e plantas naturais são exemplos dos costumes dos quilombolas guaporeanos, apontados como principais formas de enfrentamento ao adoecimento das pessoas que vivem nas comunidades. Contudo, o interesse por essas práticas vem diminuindo nos últimos anos.

O consumo excessivo de bebida alcoólica é compreendido como costume que faz parte da tradição dessas comunidades, e a iniciação ao uso de álcool parece acontecer bem cedo entre os adolescentes e é mais comum entre os homens. As mudanças ocorridas nos últimos anos, como a facilidade do acesso aos centros urbanos, bem como a chegada da energia elétrica nas comunidades, foram apontadas como um fator facilitador ao consumo excessivo de bebidas alcoólicas.

Embora os resultados obtidos respondam aos objetivos propostos, existem lacunas neste estudo que precisam ser evidenciadas. Umas dessas limitações se refere ao fato de a pesquisa ter ocorrido em apenas duas das cinco comunidades quilombolas do Vale do Guaporé, no estado de Rondônia, impossibilitando o conhecimento da realidade de outras especificidades de outras comunidades. Além disso, a realização de outros estudos com delineamentos variados com essa população poderá dar visibilidade a outras análises e problematizações não contempladas no presente estudo.

Por fim, espera-se que esses resultados possam colaborar para a construção e implementação de políticas públicas que contribuam no enfrentamento das desigualdades e na redução da vulnerabilidade social dessas comunidades.

\section{Referências}

Amorim, M. M., Tomazi, L., Silva, R. A. A., Gestinari, R. S., \& Figueiredo, T. B. (2013). Avaliação das condições habitacionais e de saúde da comunidade quilombola Boqueirão, Bahia, Brasil. Bioscience Journal, 29(4), 1049 -1057.

Bourdieu, P. (2015). A economia das trocas simbólicas. São Paulo, SP: Perspectiva.

Constituição da República Federativa do Brasil de 1988. Recuperado de https://presrepublica.jusbrasil.com.br/ legislacao/188546065/constituicao-federal-constituicao-da-republica-federativa-do-brasil-1988

Canclini, N. G. (2013). Culturas híbridas. São Paulo, SP: Universidade de São Paulo.

Caputo, S. G. (2012). Educação nos terreiros: E como a escola se relaciona com crianças de candomblé. Rio de Janeiro, RJ: Pallas.

Cardoso, L. G. V., Melo, A. P. S., \& Cesar, C. C. (2015). Prevalência do consumo moderado e excessivo de álcool e fatores associados entre residentes de comunidades quilombolas de Vitória da Conquista, Bahia, Brasil. Ciência \& Saúde Coletiva, 20(3), 809-820. https://doi.org/10.1590/1413-81232015203.12702014

Clemente, A. S., Loyola Filho, A. I., \& Firmo, J. O. A. (2011). Concepções sobre transtornos mentais e seu tratamento entre idosos atendidos em um serviço público de saúde mental. Cadernos de Saúde Pública, 27(3), 555-564. https:// doi.org/10.1590/S0102-311X2011000300015 
Psicologia: Ciência e Profissão 2019 v. 39 (n.spe), e222123,22-37.

Creswell, J. W. (2010). Projeto de pesquisa: Métodos qualitativo, quantitativo e misto. Porto Alegre, RS: Artmed.

Cruz, T. A. (2012). Um estudo comparado das relações ambientais de mulheres da floresta do Vale do Guaporé (Brasil) e do Mayombe (Angola): 1980-2010 (Tese de doutorado). Centro de Filosofia e Ciências Humanas, Universidade Federal de Santa Catarina, Florianópolis, SC.

Deschamps, J. C., \& Moliner, P. (2013). A identidade em psicologia social: Dos processos identitários às representações sociais. Petrópolis, RJ: Vozes.

Edwards, D. (2004). Psicologia discursiva: Unindo teoria e método como exemplo. In: L. Iñiguez (Org.), Manual de análise do discurso em ciências sociais (pp. 181-205). Petrópolis, RJ: Vozes.

Freitas, D. A., Caballero, A. D., Marques, A. S., Hernández, C. I. V., \& Antunes, S. L. N. O. (2011). Saúde e comunidades quilombolas: Uma revisão da literatura. Revista CEFAC, 13(5), 937-943.

Furtado, M. B., Pedroza, R. L. S., \& Alves, C. B. (2014). Cultura, identidade e subjetividade quilombola: Uma leitura a partir da psicologia cultural. Psicologia \& Sociedade, 26(1), 106-115. https://doi.org/10.1590/S010271822014000100012

Geertz, C. (2008). A interpretação das culturas. Rio de Janeiro, RJ: LTC.

Geertz, C. (2013). O saber local: Novos ensaios em antropologia interpretativa. Petrópolis, RJ: Vozes.

Gergen, K. J. (1997). Relation and relationships: Soundings in social construction. Cambridge, MA: Harvard University.

Kochergin, C. N., Proietti, F. A., \& César, C. C. (2014). Comunidades quilombolas de Vitória da Conquista, Bahia, Brasil: Autoavaliação de saúde e fatores associados. Cadernos de Saúde Pública, 30(7), 1487-1501. https://doi. org/10.1590/0102-311X00141213

Marin, R. A. (2009). Quilombolas na Ilha de Marajó: Território e organização política. In: E. P. Godoi, M. A. Menezes, \& R. A. Marin (Orgs.), Diversidade do campesinato: Expressões e categorias (pp. 229-250). São Paulo, SP: Universidade Estadual Paulista.

Marques, A. S., Freitas, D. A., Leão, C. D. A., Oliveira, S. K. M., Pereira, M. M., \& Caldeira, A. P. (2014). Atenção Primária e saúde materno-infantil: A percepção de cuidadores em uma comunidade rural quilombola. Ciência \& Saúde Coletiva, 19(2), 365-371. https://doi.org/10.1590/1413-81232014192.02992013

Melo, M. F. T., \& Silva, H. P. (2015). Doenças crônicas e os determinantes sociais da saúde em comunidades quilombolas do Pará, Amazônia, Brasil. Revista da ABPN, 7(16), 168-189.

Meneghel, S. N., \& Iñiguez Rueda, L. (2007). Contadores de histórias: Práticas discursivas e violência de gênero. Cadernos de Saúde Pública, 23(8), 1815-1824. https:// doi.org/10.1590/S0102-311X2007000800008

Oda, A. M. G. R. (2013). Escravidão e nostalgia no Brasil: O banzo. In:Y. N. Monteiro, \& M. L. T. Carneiro (Orgs.), As doenças e os medos sociais (pp. 105-132). São Paulo, SP: Universidade Federal de São Paulo.

Oliveira, S. K. M., Pereira, M. M., Guimarães, A. L. S., \& Caldeira, A. P. (2015). Self-perceived health among 'quilombolas' in northern Minas Gerais, Brazil. Ciência \& Saúde Coletiva, 20(9), 2879-2890. https:// doi.org/ 10.1590/141381232015209.20342014

Partelli, A. N. M. (2016). Histórias sobre álcool de uma comunidade quilombola contadas por adolescentes em um material educativo (Tese de doutorado). Escola de Enfermagem Anna Nery, Universidade Federal do Rio de Janeiro, Rio de Janeiro, RJ.

Pereira, M. G. S., \& Coelho-Ferreira, M. C. (2017). Uso e diversidade de plantas medicinais em uma comunidade quilombola na Amazônia Oriental, Abaetetuba, Pará. Biota Amazônia, 7(3), 57-68. http://dx.doi.org/10.18561/21795746/biotaamazonia.v7n3p57-68

Potter, J., \&Wetherell, M. (1987). Discourse and social psychology. London: Sage.

Rasera, E. F. (2013). A psicologia discursiva nos estudos em psicologia social e saúde. Estudos e Pesquisas em Psicologia, 13(3), 815-834.

Santos, A. O. (2017). Saúde mental da população negra: Uma perspectiva não institucional. Revista da ABPN, 10(24), 241-259.

Silva, R. A. D., \& Menezes, J. D. A. (2016). Reflexões sobre o uso de álcool entre jovens quilombolas. Psicologia \& Sociedade, 28(1), 84-93. https://doi.org/10.1590/1807-03102015v28n1p084 
Silva, V. H F., Dimenstein, M., \& Leite, J. F. (2013). O cuidado em saúde mental em zonas rurais. Mental, 10(19), 267285.

Silva Filho, J. B. (2012). Quilombolas: Resistência, história e cultura. São Paulo, SP: Instituto Brasileiro de Edições Pedagógicas.

Spink, M. J. P., \& Medrado, B. (2013). Uma abordagem teórico-metodológica para análise das práticas discursivas. In: M. J. Spink (Ed.), Práticas discursivas e produção de sentidos no cotidiano: Aproximações teóricas e metodológicas (pp. 22-41). Rio de Janeiro, RJ: Centro Edelstein de Pesquisas Sociais.

Teixeira, R. S., \& Pinto, A. S. (2013). Metáforas na fala de remanescentes de quilombos do Vale do Guaporé: Um estudo semântico-lexical. Revista de Estudos de Literatura, Cultura e Alteridade-Igarapé, 2(1), 137-162.

Teixeira, M. A. D., \& Xavier, D. F. B. (2018). Santo Antônio do Guaporé: Direitos humanos, conflitos e resistência socioambiental. Revista Direito e Práxis, 9(1), 351-371.

\section{Eraldo Carlos Batista}

Doutor em Psicologia pela Pontifícia Universidade Católica do Rio Grande do Sul (PUC-RS), Porto Alegre - RS. Brasil. Mestre em Psicologia pela Fundação Universidade Federal de Rondônia (UNIR), Porto Velho - RO. Brasil. Professor do Departamento de Psicologia da Faculdade Católica de Rondônia - FCR, Porto Velho - RO, Brasil E-mail: eraldo.cb@hotmail.com

(D) https://orcid.org/0000-0002-7118-5888

\section{Katia Bones Rocha}

Professora Doutora no Programa de Pós-Graduação de Psicologia da Pontifícia Universidade Católica do Rio Grande do Sul (PUCRS), Porto Alegre - RS. Brasil.

E-mail: katiabonesrocha@gmail.com

(D) https://orcid.org/0000-0001-7603-1709

Endereço para envio de correspondência:

R. Gonçalves Dias, 290 - Centro, Porto Velho - RO, CEP 76801-132

Recebido 01/04/2019

Aceito 06/05/2019

Received 04/01/2019

Approved 05/06/2019

Recibido 01/04/2019

Aceptado 06/05/2019

Como citar: Batista, E. C., \& Rocha, K. B. (2019). Sentidos e Práticas em saúde mental em comunidades quilombolas no Estado de Rondônia. Psicologia: Ciência e Profissão, 39(n.spe), 22-37. https://doi.org/10.1590/1982-3703003222123

How to cite: Batista, E. C., \& Rocha, K. B. (2019). Senses and practices in mental health in quilombola communities in the State of Rondônia. Psicologia: Ciência e Profissão, 39(n.spe), 22-37. https://doi.org/10.1590/1982-3703003222123

Cómo citar: Batista, E. C., \& Rocha, K. B. (2019). Sentidos y prácticas en salud mental en comunidades quilombolas en el Estado de Rondônia. Psicologia: Ciência e Profissão, 39(n.spe), 22-37. https://doi.org/10.1590/1982-3703003222123 